\title{
Alimentação, globalização e interculturalidade alimentar a partir do contexto migratório ${ }^{1}$
}

\section{Food, globalization and food interculturality from the migration contexto}

\author{
Carla Pires Vieira da Rocha ${ }^{2}$, Carmen Silvia Rial ${ }^{3}$, Luceni Hellebrandt ${ }^{4}$
}

\begin{abstract}
Resumo
O artigo explora a relação entre alimentação, migrações e Interculturalidade, levando em conta o cenário atual. O objetivo é destacar a alimentação em sua dimensão simbólica, como um elemento-chave de identificação dos migrantes com sua cultura de origem e, do mesmo modo, de negociação com a cultura de inserção. Nesta abordagem, a globalização exerce um papel central, contribuindo para que alguns valores, hábitos e imaginários relacionados às práticas alimentares sejam mantidos e outros reconfigurados. O texto contempla uma perspectiva teórica Interdisciplinar baseada principalmente nos aportes da História da Alimentação, da Sociologia e da Antropologia.
\end{abstract}

Palavras-chave: Alimentação. Migrações. Globalização. Interculturalidade.

\begin{abstract}
The article explores the relationship between food, migration and Interculturality, taking into account the current scenario. The aim is to highlight the food in its symbolic dimension, as a key element of identifying migrants with their culture of origin and, likewise, negotiation with the culture insert. In this approach, globalization plays a central role in contributing to some values, habits and imaginary related to feeding practices are maintained and reconfigured others. The text features an interdisciplinary theoretical perspective based mainly on the contributions of the History of Food, Sociology and Anthropology.
\end{abstract}

Keywords: Food. Migration. Globalization. Interculturality.

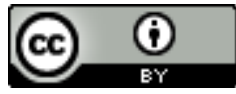

Esta obra foi licenciada com uma Licença Creative Commons - Atribuição 3.0 Não

Adaptada.

\footnotetext{
${ }^{1}$ Este texto é uma versão modificada do original: "Tapas" ou "Coxinha": uma análise das relações entre alimentação, migração e interculturalismo a partir de blogs de brasileiros na Espanha apresentado no II CONINTER - Congresso Internacional Interdisciplinar em Sociais e Humanidades (Belo Horizonte, MG, outubro de 2013).

2 Doutoranda do Programa de Pós-Graduação Interdisciplinar em Ciências Humanas da Universidade Federal de Santa Catarina. E-mail: carlapvrocha@gmail.com

3 Professora do Programa de Pós-Graduação Interdisciplinar em Ciências Humanas da Universidade Federal de Santa Catarina. E-mail: rial@cfh.ufsc.br

4 Doutoranda do Programa de Pós-Graduação Interdisciplinar em Ciências Humanas da Universidade

Federal de Santa Catarina. E-mail: Iuceni.hellebrandt@gmail.com

Cad. de Pesq. Interdisc. em Ci-s. Hum-s. Florianópolis, Santa Catarina, Brasil, ISSN 1984-8951
} v.14, n.105, p.187-199, ago/dez 2013 


\section{Introdução}

Os deslocamentos e as migrações não são novidade, mas o atual momento do capitalismo mundial acelerou estes movimentos populacionais, como em outros momentos da história já o tinha requerido - por exemplo, nas grandes transumâncias forçadas entre a África , a Europa e a América a partir do século XVI, que garantiram a expansão colonial europeia. No Brasil, da década de 80 do século $\mathrm{XX}$ em diante, observamos uma mudança no sentido dos deslocamentos laborais: as saídas passando a predominar sobre as entradas, a emigração sobre a imigração e as entradas passando a ser predominantemente de latino-americanos, do Oriente Médio e asiáticos. Trata-se de um cenário novo, pois o país tradicionalmente recebeu pessoas, fossem escravos ou os imigrantes que compuseram a grande onda migratória de 1880 a 1930 (Lesser, 1999).

A migração, seja resultado de uma escolha ou não, implica bem mais que uma mudança geográfica; em quaisquer situações, significa uma reelaboração de muitos elementos que colaboram cotidianamente para reforçar o sentido de identidade. Nesse processo, a alimentação assume extrema relevância: situa-se na interface entre o país de inserção e o de origem, entre o indivíduo migrante e o seu país, região ou família. Em tal dinâmica, estão envolvidas distintas expressões socioculturais, colocando em cena a necessidade de constantes negociações.

Na síntese de Contreras (2011, p. 129), a noção de cultura alimentar expressa "o conjunto de representações, crenças, conhecimentos e práticas herdadas e/ou aprendidas que estão associados à alimentação e são compartilhados pelos indivíduos de uma determinada cultura ou grupo social". Assim, a compreensão de como se dá a adaptação a outra cultura alimentar exige considerar que o ato de ingerir um alimento não se resume a uma função biológica; enquanto fenômeno complexo, a alimentação inclui outras dimensões, como a imaginária, a simbólica e a social (Fischler, 1995). Na mesma concepção, cada cozinha abarca especificidades e, no caso do imigrante, incluir novos ingredientes na dieta pode indicar uma forma de apropriação daquele novo território. Do mesmo modo, reproduzir pratos da cultura de origem, além de refletir a resistência ao abandono de certas práticas alimentares, consiste na possibilidade da sua ressignificação naquele outro contexto. 
No panorama contemporâneo, a globalização vem acelerando a comunicação entre as diferentes culturas culinárias ${ }^{5}$. Embora não se restrinja à esfera alimentar, a materialização desse fenômeno reconfigura o campo de diversas maneiras. Assim como não é raro optar por "coxinha" ao invés de tapas em algum lugar da Espanha, se deparar com a oferta de itens alimentares provenientes do Brasil é cada vez menos inusitado.

Levando em conta essas considerações iniciais, este artigo tem como fim explorar a relação entre alimentação, migração e a interculturalidade, ou seja, as negociações realizadas pelos agentes no contexto contemporâneo. Será considerada a perspectiva sociocultural, onde as questões de identidade e aspectos da globalização exercerão um papel decisivo.

\section{0 fenômeno migratório brasileiro: interlocuções com a Espanha}

O Brasil é um país sabidamente marcado pelas imigrações. Sua constituição histórica, social e cultural carrega fortes traços de diferentes povos e etnias que vieram a configurar a fisionomia deste território. Por outro lado, a emigração, embora um fenômeno mais recente, é também bastante significativa para se pensar a dinâmica global contemporânea, especialmente no que concerne às trocas entre indivíduos deslocados e seus locais de origem.

Tomando como referência o período entre 1819 e o final da década de 1940, o Brasil recebeu cinco milhões de migrantes entre italianos, portugueses, espanhóis, alemães e japoneses. Ainda que menos expressivos numericamente, também se incluíram grupos migratórios de russos, austríacos, sírio-libaneses e poloneses. Inicialmente, esses movimentos foram estimulados por políticas migratórias implementadas pelo governo imperial. Posteriormente, em uma conjuntura nacional de transição do trabalho escravo para o trabalho livre, as migrações foram impulsionadas com a finalidade de se substituir a mão de obra escrava.

Já o movimento de emigração intensificou-se a partir da década de 1990. Atribui-se às dificuldades econômicas atravessadas pelo país e aos altos índices de

\footnotetext{
5 Rial, Carmen. McDonaldisation - Dictionnaire des cultures alimentaires. In: Jean-Pierre Poulain. (Org.). Dictionnaire des cultures alimentaires. 1ed. Paris: Press Universitaire de France, 2012, v. 1, p. 56-62.
} 
inflação naquele período como alguns dos principais fatores desencadeadores desse processo (Cogo e Souza, 2013).

De acordo com o Ministério das Relações Exteriores, o número de brasileiros no exterior até o ano de 2008 era estimado em 3 milhões ${ }^{6}$. Hoje, as dificuldades financeiras enfrentadas por muitos dos países de destino dos brasileiros, o crescimento da taxa de desemprego e controles migratórios mais rígidos dos governos com relação à entrada e permanência de estrangeiros em seus territórios, vêm influenciando na decisão de regresso ao Brasil. Paralelamente, as mudanças na situação econômica deste país e, consequentemente, as novas oportunidades de trabalho que surgiram, vêm igualmente se tornando fatores de atração para o retorno de emigrantes. Todavia, mesmo em virtude desse panorama, o número dos que seguem vivendo no exterior ainda é alto; dados do governo brasileiro apontam a cifra aproximada de 2,5 milhões em $2012^{7}$.

Depois dos Estados Unidos, Japão, Paraguai e Reino Unido, a Espanha é o país com maior contingente de migrantes procedentes do Brasil. Em 2011, o número foi avaliado em cerca de 158.761 pessoas (Cogo e Souza, ibidem). As Comunidades Autônomas da Catalunha e de Madri concentram a maior parcela desses migrantes. De acordo com Masanet e Baeninger (2011), as oportunidades de emprego nas duas comunidades e, em particular, nas suas capitais, explicam a presença significativa da população brasileira em tais espaços.

A Espanha é o quarto maior país da Europa e ocupa a parte mais extensa da Península Ibérica. Faz fronteira ao norte com a França, a oeste com Portugal e ao sul com o Marrocos. Seu território é delimitado a leste e ao sul pelo mar Mediterrâneo. Essa geografia, além de exercer forte influência no clima do país, favoreceu o desenvolvimento da celebrada dieta mediterrânea, valorizada como um modelo de dieta tradicional e largamente associada à promoção da saúde.

Entretanto, a cultura alimentar espanhola está ancorada acima de tudo em suas cozinhas regionais. O fato de situar-se no cruzamento entre outros países da Europa e o norte da África determinou um melting pot que inclui influências árabes e ingredientes do continente americano (Medina, 2005). Nas palavras de Contreras

\footnotetext{
6 Disponível em: <http://www.brasileirosnomundo.itamaraty.gov.br/noticias/censo-ibge-estima-brasileiros-noexterior-em-cerca-de-500-mil/impressao> [Acesso em 15 julho 2013].

${ }^{7}$ Disponível em: <http://www.brasileirosnomundo.itamaraty.gov.br/a-comunidade/estimativas-populacionais-dascomunidades> [Acesso em 15 julho 2013].
}

Cad. de Pesq. Interdisc. em Ci-s. Hum-s. Florianópolis, Santa Catarina, Brasil, ISSN 1984-8951 v.14, n.105, p.187-199, ago/dez 2013 
(2011, p. 443), o país espanhol é um exemplo de pluralidade culinária; historicamente, é um espaço constituído de encontros e desencontros entre as cozinhas que foram migrando e se instalando naquele território.

Semelhante ao que ocorre na Espanha, a ideia de uma "cozinha brasileira" envolve a noção da diversidade de povos que viveram e ainda vivem neste território $^{8}$. Do mesmo modo, deve levar em conta que as cozinhas estão sujeitas a constantes transformações e contínuas recriações (Maciel, 2004). Nesse sentido, um olhar muito breve pode ficar restrito a alguns estereótipos de ambas as culinárias: assim como a alimentação na Espanha não se reduz à paella, no Brasil, o que se come vai bem além da feijoada.

$\mathrm{Na}$ abordagem das questões envolvidas na adaptação a uma determinada cultura alimentar, especialmente no contexto das migrações, é importante sublinhar que a cultura não é estática e tampouco transportável e medível, mas dissolúvel e escorregadia, construída na interação e por meio das práticas sociais contextualizadas. Dessa forma, torna-se difícil demarcar suas fronteiras (Castaño e Ruiz-Matas, 2010).

Assim, cabe ainda considerar o impacto da progressiva globalização da indústria agroalimentar não apenas no comportamento relacionado aos alimentos, como também nas práticas concernentes ao seu consumo. A mundialização dos mercados e a ampliação das redes distribuidoras e de transportes tornaram disponível uma variedade de itens em diferentes locais e em zonas geograficamente distantes. Desta forma, fazer um pão de queijo ou saborear uma "coxinha" na Espanha é uma experiência cada vez menos incomum.

\footnotetext{
${ }^{8}$ Sobre a concepção de uma "cozinha brasileira" baseada na etnicidade, ou seja, nas contribuições dos índios, negros e brancos, Maciel (2004, p.28) assinala que "o que se chama hoje de "cozinha brasileira" é o resultado de um processo histórico, o qual traz em si elementos das mais diversas procedências que aqui foram modificados, mesclados e adaptados. Não é possível pensar em uma "cozinha brasileira" sem pensar em uma miscigenação. Porém, essa constatação não implica uma apologia desta, nem uma essencialização de uma situação que é dinâmica. Nessa perspectiva, ao se afirmar que a cozinha brasileira é marcada pelos diferentes povos que viveram e vivem em seu território, reafirma-se o papel e a participação desses povos, rompendo com uma visão de harmonia que implica o "mito" da democracia racial. Colocando o fenômeno num quadro de conflitos e desigualdades, não dá para ignorar que o português branco colonizador foi instaurador da hierarquia, que o negro foi trazido à força e que o índio foi, em grande medida, dizimado. Não é possível, assim, colocar as "três raças" em um plano horizontal e, se este é o país das hierarquias internalizadas, cabe verificar como isso se expressa". Reconhecemos em Gilberto Freyre (2006) o pioneirismo em apontar esta mescla mas, concordando com a autora acima, pensamos que originalmente a "cozinha brasileira" foi marcada pelo conflito e não pela harmonia entre dominantes e subalternos, como entendia o autor pernambucano.
} 
Levando em conta esta primeira contextualização, a seguir, tomando como referência a versão anterior deste texto que analisou relatos presentes em blogs de imigrantes brasileiros na Espanha9, visaremos delinear as seguintes questões: De que maneira a alimentação interfere na experiência migratória? Em que medida contribui ou dificulta a adaptação a um outro território? Qual o impacto da globalização alimentar na alimentação de migrantes? Até que ponto a alimentação promove o diálogo entre diferentes culturas culinárias?

\section{Comida, fluxos globais e interculturalidade alimentar}

Neste início de século, a alimentação no contexto migratório deve ser examinada levando-se cada vez mais conta um quadro de progressiva globalização. Se a industrialização dos alimentos é um fator crucial para se pensar as modificações neste campo, a sua distribuição em larga escala não é menos importante; a par de redimensionar o consumo, vem repercutindo na experiência migratória, tornando-se igualmente um elemento-chave para se pensar a interculturalidade relacionada à esfera alimentar, em especial, no que se refere às práticas alimentares de brasileiros no exterior e suas negociações com o local .

O historiador Massimo Montanari (2008) lembra que é mais fácil entrar em contato com a cultura do outro comendo a sua comida que decodificando sua língua. Ainda que o conceito de "cultura" nos pareça reduzir as heterogeneidades e abranger contextos muito diversos sob um mesmo termo, podemos concordar com o autor quando aponta que a comida é um atalho para se aproximar, pelos sentidos e intelectualmente, de outros sujeitos com outra práticas e concepções de mundo, facilitando (ou não) os diálogos. Para Walsh (apud Candau, ibiden, p.52), a interculturalidade, entre outros aspectos, é definida como um "intercâmbio que se constrói entre pessoas, conhecimentos, saberes e práticas culturalmente diferentes, buscando desenvolver um novo sentido entre elas na sua diferença". Seguindo esta concepção, a alimentação pode ser vista como um elemento de interculturalidade. Contudo, no que concerne à alimentação, esse processo não é tão simples.

\footnotetext{
9 "Tapas" ou "Coxinha": uma análise das relações entre alimentação, migração e interculturalismo a partir de blogs de brasileiros na Espanha disponível em: <www.2coninter.com.br/artigos/pdf/790.pdf>

Cad. de Pesq. Interdisc. em Ci-s. Hum-s. Florianópolis, Santa Catarina, Brasil, ISSN 1984-8951 v.14, n.105, p.187-199, ago/dez 2013
} 
Quando se deixa o país, muito do que dá sentido à vida cotidiana pode ficar para trás. Todavia, os hábitos alimentares são os que mais resistem ao abandono. Isso porque a comida, mais que a ingestão do alimento, envolve variadas dimensões. Lembra Contreras (2011) que, além dos procedimentos culinários, a cozinha ainda inclui um conjunto de regras, de práticas, de representações simbólicas e valores, determinando aquilo que é comestível e o que não é, e construindo assim o conjunto de nossas preferências e aversões alimentares por meio dos saberes e habilidades técnicas. Estes, tradicionalmente transmitidos de geração a geração, são assimilados e perpetuados entre os membros de uma determinada sociedade. Nessa medida, torna-se possível compreender por que determinados hábitos relacionados aos alimentos persistem ou a razão pela qual as diferenças na alimentação podem causar surpresa, estranheza, desconfiança ou mesmo repulsa.

A partir da análise dos relatos de migrantes brasileiros na Espanha, acima mencionada, foi possível delinear algumas das questões que permeiam a relação entre alimentação e migração. É de se destacar que a alimentação emerge como um fator determinante no processo de adaptação dos referidos migrantes àquela outra cultura.

Nos relatos analisados, a comida igualmente é expressa como um dos componentes decisivos para a afirmação de identidades. Como assinala o sociólogo Claude Fischler (1995), ao ingerirem um alimento, as pessoas são incorporadas a um sistema culinário - práticas materiais e simbólicas - e a um determinado grupo que o pratica. A comida, portanto, configura-se um importante elemento identitário, pelo qual os grupos sociais tomam consciência da sua diferença e de sua etnicidade, de maneira que compartilhá-la pode significar o reconhecimento e a aceitação/incorporação de tais diferenças (Contreras, 2011).

Por outro lado, como argumenta Hall (2002, p.75), quanto mais a vida social se torna mediada pelo mercado global de estilos, lugares e imagens, pelas viagens internacionais, pelas imagens da mídia e pelos sistemas de comunicação globalmente interligados, mais as identidades se tornam desvinculadas desalojadas - de tempos, lugares, histórias e tradições específicos, e parecem "flutuar livremente". Mesmo discordando de Hall, quando aponta que temos livre escolha ao sermos confrontados por uma gama de diferentes identidades, podemos 
aceitar que, numa situação de deslocamento, como é o caso da imigração, a comida permite tanto alimentar identidades relacionadas ao país de origem, quanto se constituir em uma chave de identificação com outros contextos culturais.

A noção de tradição associada à alimentação também foi um elemento significativo nos relatos, no sentido de se compreender como determinados pratos acabam reforçando certas identidades alimentares. Do mesmo modo, como chama a atenção Giddens (2003), as tradições são necessárias às sociedades, porque contribuem tanto para a continuidade como para a formação da vida social.

Segundo Montanari (2008, 2009), cada tradição alimentar é o fruto sempre provisório de uma série de inovações e de adaptações, pois é um produto da história, gerado por complexos fenômenos de troca, cruzamento e contaminação. Já para Carrasco i Pons (2005, p.103), e, no que tange aos grupos em situação migratória, a tradição alimentar se refere à origem e à recordação; de alto valor simbólico, tende a se readaptar culinariamente para ser utilizada como identidade.

Assar um churrasco em território espanhol poder ser ilustrativo das considerações de ambos os autores supracitados: essa prática, assim como envolve trocas e adaptações, também inscreve os imigrantes como atores que facilitam a circulação das suas culturas culinárias, reiterando desta forma 0 potencial comunicativo da alimentação em uma dimensão intercultural.

A análise dos relatos de brasileiros que emigraram para a Espanha e se expressam através dos blogs, mostrou um outro ponto determinante a ser destacado, qual seja, o do impacto da globalização da indústria agroalimentar no consumo alimentar dos migrantes. Se muitos alimentos eram anteriormente restritos a um determinado território, em virtude da aceleração de tal processo, passaram a estar disponíveis num âmbito bem mais amplo, repercutindo de maneira singular no contexto migratório.

Como ilustrativo da dinâmica global dos fluxos de produtos alimentares em vigor, cabe fazer referência à crescente exportação de produtos brasileiros, cujo mercado é voltado prioritariamente para atender a demanda migratória. Sites de grandes lojas importadoras como é o caso do Delícias Latina10, na capital espanhola ou o Finalmente Brasil11, na Holanda, vêm se tornando elucidativos

\footnotetext{
${ }^{10}$ Disponível em: <http://www.deliciaslatina.es/14-ofertas > Acesso em Dezembro/2013.

${ }^{11}$ Disponível em: <http://www.finalmentebrasil.nl/loja/home.html> Acesso em Dezembro/2013.

Cad. de Pesq. Interdisc. em Ci-s. Hum-s. Florianópolis, Santa Catarina, Brasil, ISSN 1984-8951

v.14, n.105, p.187-199, ago/dez 2013
} 
desse panorama: lojas que, tanto em seu ambiente físico como no virtual, oferecem diferentes categorias de itens alimentares brasileiros, incluindo cervejas, polpa de frutas, doces, farinhas, sucos, enlatados, entre outros. Outro exemplo é Vícios Brasileiros12, direcionado ao consumo na Alemanha, embora circunscrito exclusivamente ao comércio virtual de alimentos.

O fluxo de pessoas, que nos últimos anos levou cerca de três milhões de brasileiros para os exterior, se fez assim acompanhar de um fluxo de de mercadorias, dentre as quais se destacam os alimentos. São eles os principais itens importados por estas lojas na Europa, que pode chegar, como no caso do Finalmente Brasil, a oito containers de mercadoria por ano. Trata-se de um comércio que pode ser insignificante financeiramente, se comparado aos alimentos exportados pelo Brasil para diversos países do mundo (tais como a soja, a carne bovina, ovina e suína), mas que é extremamente significativa simbolicamente, pois reconstrói cotidianamente a identidade para estes imigrantes, mantendo-os imaginariamente, ao menos no tempo em que dura a refeição, de volta ao Brasil.

Tais exemplos são enunciadores da dinâmica atual, quando a globalização dos mercados e das comunicações é intensificada pela aceleração dos fluxos de pessoas, informações, capitais, bens culturais, serviços, tecnologias, entre outros. Além de afetar tanto os grandes como os pequenos grupos, a atual globalização, nas palavras de Giddens (2003, p. 29), no lugar de algo "firme e seguro", é repleta de ansiedades e profundas divisões.

No que concerne aos alimentos, esse fluxo revela mais que distintas formas de mobilidade ou desterritorialização (Ortiz, 1994); os inscreve como produtos imersos em uma "cultura mundial" (Hannerz, 1990), impulsionada pela interconectividade de culturas locais variadas. E esta configuração naturalmente implica diferentes formas de apropriação e valorização na esfera alimentar.

Como se dá essa apropriação? Que valores estão envolvidos? Em que medida este consumo difere daquele em seu contexto original? Embora responder estas indagações fuja da proposta inicial do texto, a sua formulação pretende ser oportuna para evidenciar não apenas as possibilidades de reflexão que se abrem diante do tema, mas a sua própria complexidade.

\footnotetext{
${ }^{12}$ Disponível em: http://www.vicios-brasileiros.de/index.php?language=pt Acesso em Dezembro/2013. Cad. de Pesq. Interdisc. em Ci-s. Hum-s. Florianópolis, Santa Catarina, Brasil, ISSN 1984-8951
} 


\section{Considerações finais}

Tornar-se um emigrante significa deixar para trás grande parte do que reforça cotidianamente nosso sentido de identidade. Por outro lado, implica levar na bagagem um conjunto de valores, de crenças, de imaginários que ora atuam como elementos de resistência à adaptação a um contexto social, ora contribuem em sentido positivo para reconfigurar a experiência migratória. Nesta medida, a alimentação adquire um papel fundamental.

Deslocar-se para um país distante nem sempre é um processo fácil, especialmente no que diz respeito à alimentação. A cozinha do imigrante sofre modificações para se adaptar ao novo ambiente. Mesmo assim, os hábitos relacionados aos alimentos persistem e reproduzir um prato expressivo da cultura alimentar de origem, mesmo que necessária a improvisação de alguns ingredientes, permite reforçar laços identitários e de pertencimento a uma determinada sociedade.

No panorama contemporâneo, a globalização vem exercendo um impacto decisivo nas migrações. No que se refere às práticas alimentares, num mundo em que a intensificação das trocas e intercâmbios se dá, muitas vezes, de maneira assimétrica, acirrando as desigualdades e diferenças, a comida pode atuar como um elo com o país de origem, ao mesmo tempo em que pode favorecer a partilha de experiências e a comunicação entre os diferentes grupos culturais. 


\section{Referências}

BLOOD, R. WEBLOGS: A History and Perspective. Rebecca's Pocket. 7 Set 2000. Disponivel em <http://www.rebeccablood.net/essays/weblogs_history.html>. [Acesso em 23 julho 2013].

CANDAU, V. M. Direitos Humanos, educação e interculturalidade: as tensões entre igualdade e diferença. Revista Brasileira de Educação. 13, 37, 45-56, 2008

CARRASCO I PONS, S. Pontos de partida teórico-metodológicos para o estudo sociocultural da alimentação em um contexto de transformação. In: Canesqui, Ana Maria (org.). Antropologia e nutrição: um diálogo possível. Rio de Janeiro, Editora Fiocruz, 2005, p.101-128.

Disponível em http://bvsms.saude.gov.br/bvs/publicacoes/cd10_01.pdf [Acesso em 12 junho 2013].

CASTAÑO, F. G. G.; RUIZ-MATAS, C. B. Sociedad multicultural e interculturalismo versus inmigración extranjera: aportaciones teóricas para el debate. Documentación Social - El desafío de las migraciones. 21, Madrid, Cáritas Española Editores, 2000.

COGO, D. M. Mídia, interculturalidade e migrações contemporâneas. Rio de Janeiro, E-papers, Brasília, DF, CSEM, 2006.

COGO, D. M; SOUZA, M. B. Guia das Migrações Transnacionais e diversidade cultural para comunicadores - migrantes no Brasil. Bellaterra, Instituto Humanitas Unisinos; Instituto de la Comunicacion de la UAB, 2013. Disponível em: http://www.guiamigracoesdivcult.com/ [Acesso em 2 Agosto 2013].

CONTRERAS, J. Patrimônio e globalização: o caso das culturas alimentares. In: Canesqui, A. M. (org.). Antropologia e nutrição: um diálogo possível. Rio de Janeiro, Editora Fiocruz, 2005. p. 129-146.

CONTRERAS, J. Alimentação, sociedade e cultura. Rio de Janeiro, Editora Fiocruz, 2011 
FISCHLER, C.. El (h)omnívoro: el gusto, la cocina y el cuerpo. Barcelona: Anagrama, 1995.

HALL, S. A identidade cultural na pós-modernidade. 7 ed. Rio de Janeiro, DP\&A. 2002.

FREYRE, G. Casa-grande \& senzala: formação da família brasileira sob o regime de economia patriarcal. 51 ed. Rev. São Paulo: Global, 2006.

GIDDENS, A. Mundo em descontrole: o que a globalização está fazendo de nós. 3 ed. Rio de Janeiro: Record, 2003.

HANNERZ, U. Cosmopolitans and Locals in World Culture. In: Transnational Connections.Culture, People and Places. Londres. SAGE, 1990. p. 237-251. Disponível em: http://tcs.sagepub.com

LESSER, J. Negotiating National Identity: Immigrants, Minorities, and the Struggle for Ethnicity in Brazil. Durham, NC: Duke University Press, 1999.

MACIEL, M. E. Uma cozinha à brasileira. Revista Estudos Históricos, Brasil, 1, jun. 2004.Disponível em: http://bibliotecadigital.fgv.br/ojs/index.php/reh/article/view/2217/1356 [Acesso em 04 Agosto 2013].

MEDINA, F. X. Food culture in Spain. Library of Congress, USA, 2005.

MASANET, E. BAENINGER, R.. Brasileiros e brasileiras na Espanha: mercado de trabalho, seguridade social e desemprego. Revista Paranaense de Desenvolvimento, Curitiba, 121, 65-89, ju./dez., 2011.

MONTANARI, M. Comida como cultura. São Paulo, Ed. Senac, 2008. 
MONTANARI, M A cozinha, lugar da identidade e das trocas. In: Montanari, M. (org.). $O$ mundo na cozinha: história, identidade, trocas. São Paulo, Estação Liberdade, 2009. p11-17.

ORTIZ, R. Mundialização e cultura. São Paulo: Brasiliense, 1994

RIAL, C. McDonaldisation - Dictionnaire des cultures alimentaires. In: Jean-Pierre Poulain. (Org.). Dictionnaire des cultures alimentaires. 1ed. Paris: Press Universitaire de France, 2012, v.1, p.56-62.

RIAL, C. S.; KRAIESKI, V. As viagens da comida: notas a partir de etnografias de brasileiros emigrantes na região de Boston e com futebolistas que circulam no mundo. In: Silvia Arend, Carmen Rial, Joana Pedro. (Org.). Diásporas, Mobilidades e migrações. 1ed. Florianópolis: Mulheres, 2011, v. 1, p. 191-220.

Artigo:

Recebido em: 21/08/2013

Aceito em: 06/12/2013 